\title{
STUDY OF POSTERIOR CONDYLAR CANAL IN ADULT HUMAN SKULLS AND ITS CLINICAL IMPORTANCE
}

\section{Dakshayani K.R ${ }^{1}$, Uma Shivanal *2.}

${ }^{1}$ Professor \& HOD, Mysore medical college \& research institute, Mysuru, Karnataka, India.

${ }^{* 2}$ Assistant Professor, Mysore medical college \& research institute, Mysuru, Karnataka, India.

\section{ABSTRACT}

Introduction: The posterior condylar canal opens at the base of the skull just behind the occipital condyles. Posterior condylar canal is the largest emissary foramen of the posterior cranial fossa. The posterior condylar vein exits the skull through the posterior condylar (or condyloid) canal, which is a communication between the jugular foramen and the condylar fossa. The present study was taken to notethe normal anatomic pattern and variations of posterior condylar canal.

Aims and objectives: To note the presence of bilateral or unilateral and absence of posterior condylar canal (foramen).

Materials and methods: The present study was performed on 50 dry adult human skulls of unknown sex collected from the department of anatomy, Mysore medical college and research institute, Mysore. Skulls were examined by direct observation for bilateral and unilateral presence or absence of posterior condylar canal.

Results: Of the 50 human dry skulls, we observed presence of bilateral posterior condylar canal (foramina) in 18 skulls, unilateral (right) in 10 skulls and unilateral (left) in 12 skulls. The absence of posterior condylar canal (foramina) in 10 skulls.

Conclusion: Anatomical variations of posterior condylar canal are important for Neurosurgeons and ENT Surgeons, which gives them a comprehensive knowledge to operate in the vicinity of occipital condylar regions.

KEYWORDS: Posterior condylar canal, fossa, emissary veins.

Corresponding Author: Dr. Uma Shivanal, Assistant Professor, Department of Anatomy, Mysore medical college \& research institute, Mysuru, Karnataka, India.

E-Mail: umavijay15@gmail.com

Access this Article online

Quick Response code

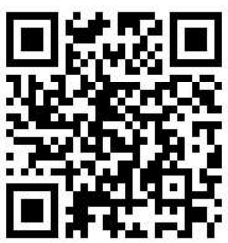

DOI: $10.16965 /$ ijar.2019.373

Journal Information

International Journal of Anatomy and Research

ICV for 2016 ISSN (E) 2321-4287 | ISSN (P) 2321-8967

90.30 https://www.ijmhr.org/ijar.htm DOI-Prefix: https://dx.doi.org/10.16965/ijar

Article Information

Received: 28 Dec 2019

Peer Review: 30 Dec 2019

Revised: None
Accepted: 23 Jan 2020

Published (O): 05 Feb 2020

Published (P): 05 Feb 2020

\section{INTRODUCTION}

Anterior part of the occipital condyle presents a canal called as hypoglossal canal or anterior condylar canal, whereas posterior to the occipital condyle, there is a depression known as posterior condylar fossa [1]. The superior articular facet of the atlas is accommodated within this fossa during the movements of the atlantooccipital joint. Within this fossa, a foramen may be present, which is called as the condylar canal or the posterior condylar canal [2]. Posterior condylar canal is the largest emissary foramen of the posterior cranial fossa. It is apparent just posteroinferior to the jugular foramen and posterior to the hypoglossal canal [3]. The posterior condylar canal opens at the groove for sigmoid sinus, posterolateral to the jugular foramen in the posterior cranial fossa. [4] Emissary channels include the sphenoid emissary vein (via the foramen of 
Vesalius), the mastoid emissary vein, the occipital emissary vein, foramen ovale emissary sinuses, and the posterior condyloid vein. Recently described emissary foramina include the inferior and lateral rotundal canals [5].

The posterior condylar vein exits the skull through the posterior condylar (or condyloid) canal, which is a communication between the jugular foramen and the condylar fossa, situated just posterior to the occipital condyles on either side of the foramen magnum. This canal allows for venous anastomosisbetween the jugular bulb and the suboccipital venous plexus [6]. Posterior condylar canal also transmits meningeal branches of the occipital artery [1].

\section{MATERIALS AND METHODS}

The present study was performed on 50 dry adult human skulls of unknown sex collected from department of anatomy, Mysore medical college and research institute, Mysore. Skulls were examined by direct observation for bilateral and unilateral presence or absence of posterior condylar canal.

\section{RESULTS}

Of the 50 human dry skulls, we observed presence of bilateral posterior condylar foramina in 18skulls, unilateral (right) in 10 skulls and unilateral (left) in 12 skulls. The absence of posterior condylar foramina was found in 10skulls.

Table 1: posterior condylar canal.

\begin{tabular}{|c|c|c|}
\hline $\begin{array}{c}\text { Posterior condylar } \\
\text { canal }\end{array}$ & No of Skulls & Percentage (\%) \\
\hline Bilateral & 18 & 36 \\
\hline Unilateral (right) & 10 & 20 \\
\hline Unilateral (left) & 12 & 24 \\
\hline Absence (fossa) & 10 & 20 \\
\hline
\end{tabular}

Fig. 1: Bilateral posterior condylar canal.

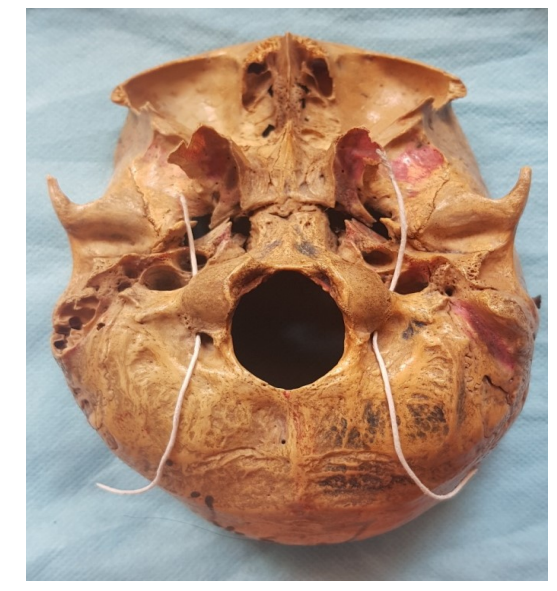

Fig. 2: Right posterior condylar canal

Fig. 3: Left posterior condylar canal

Fig. 4: Absence of canal (fossa).

\section{DISCUSSION}

Posterior condylar foramen is the most constantly present emissary foramen in human skull. It is also considered as largest emissary foramen present in humans. Posterior condylar vein passes through posterior condylar foramen. Emissary veins connect dural venous sinuses present inside the cranium to veins present outside i.e. extracranial veins. Some emissary veins are more commonly present while others are rarely found. Emissary veins are important clinically because infections from outside cranial cavity can spread to dural venous sinuses. So infection can spread from mastoid to sigmoid sinus or from paranasal sinuses to cavernous sinus. A posterior condylar emissary 
vein connects sigmoid sinus and veins in the suboccipital triangle via posterior condylar canal. An occipital emissary vein usually connects the confluence of sinuses with occipital vein through occipital protuberance. These emissaryve insprovide an alternative venous drainage when internal jugular vein is blocked or tied [7]. Condylar veins are also important channels of venous drainage for posterior cranial fossa region. These emissary veins are important in equalising intracranial pressure and they can act as safety valves in cerebral congestion [8].

During embryonic period the posterior condylar canal acts as an important route for venous circulation connecting intracranial venous sinuses with extracranial venous system. With gradual change from foetal to neonatal circulation this venous system atrophies leading to closure of venous bone tunnel. Failure of closure will lead to persistence of the posterior condylar canal [9].

Boyd (1930) reported posterior condylar canal to be present on both sides in $46.6 \%$ of skulls, absent on both sides in 23.81 percent. In unilateral cases, posterior condylar foramen was more common on right side (16.5\%) than on left side
(13.88\%)[8].Ginsberg (1994) found posterior condylar canal to be present bilaterally 19 skulls (55.9\%). In 6 skulls (17.6\%), posterior condylar canal was present on one side only (unilateral). Unilateral distribution was equal on right and left side on gross examination study [5]. Krause (1998) found $21 \%$ bilaterally presence while unilateral was $38 \%$ of skulls [10]. Manoj Kumar (2015), observed the percentage of bilateral presence of posterior condylar canal was $48.33 \%$, left unilateral presence was $18.33 \%$ and right unilateral was $15 \%$ and the canal was absent in $16.66 \%$ of skulls [11]. S. Kavitha , A Anand (2013), found patent foramen in $62.58 \%$ of skulls and it was more on right side $69.5 \%$ and left side $30.4 \%$ [12].

In present study, out of 50 skulls studied, $18(36 \%)$ skulls showed bilateral presence of posterior condylar canal, right unilateral in $10(20 \%)$ skulls which is almost similar to the study done by Ginsberg, left unilateral presence was seen in 12 (24\%) skulls higher than right side and canal was absent in $10(20 \%)$ skulls which is almost similar to the study done by Boyd. Compared to other studies, bilateral presence of posterior condylar canal is less in our study.

Table 2: Comparison of posterior condylar canal with previous studies.

\begin{tabular}{|c|c|c|c|c|}
\hline \multirow{2}{*}{ Authors } & \multirow{2}{*}{$\begin{array}{c}\text { Bilateral } \\
\text { (\%) }\end{array}$} & \multicolumn{2}{|c|}{ Unilateral } & \multirow{2}{*}{ ABSENCE (\%) } \\
\cline { 3 - 4 } & RT (\%) & LT (\%) & \\
\hline Boyd (1930) [8] & 46.6 & 16.5 & 13.88 & 23.81 \\
\hline Ginsberg (1994) [5] & 55.9 & 17.6 & 17.6 & ---- \\
\hline Manoj Kumar (2015) [11] & 48.33 & 15 & 18.33 & 16.66 \\
\hline S. Kavitha, A Anand (2013) [12] & ----- & 69.5 & 30.4 & ----- \\
\hline PRESENT STUDY & $\mathbf{3 6}$ & $\mathbf{2 0}$ & $\mathbf{2 4}$ & $\mathbf{2 0}$ \\
\hline
\end{tabular}

\section{CONCLUSION}

The basic knowledge of anatomical variations of posterior condylar canal is important for Neurosurgeons and ENT surgeons during transcondylar approaches. Thus the study gives basic knowledge to surgeons before operating inthe vicinity of occipital condylar regions.

Condylar veins can also be used as access route to dural arteriovenous fistulas involving hypoglossal canal and transverse- sigmoid dural arteriovenous fistulas with occlusion of jugular vein. Sometimes condylar vein itself can be involved in arteriovenous fistula. So understanding of normal anatomy and variations of posterior condylar vein and foramen are ofprime importance while considering treatment for arteriovenous fistulas of posterior cranial fossa region.

\section{Conflicts of Interests: None}

\section{REFERENCES}

[1]. Williams PL, Warwick R, Dyson M, Bannister L. Gray's Anatomy, 37thedn. New York, NY: Churchill Livingstone, 1989. pp. 286-7.

[2]. Hacker H. Normal supratentorial veins and dural sinuses. In: Newton TH, Potts DG, eds. Radiology of the Skull and Brain: the Skull. St. Louis, MO: Mosby, 1971. Vol 2. pp. 1851-77.3 
[3]. Matsushima T, Natori Y, Katsuta T, Ikezaki K, Fukui $\mathrm{M}$, Rhoton AL. Microsurgical anatomy for lateral approaches to the foramen magnum with special reference to transcondylar fossa approach. Skull Base Surg. 1998;8(3):119-25.

[4]. Hollinshead WH, Rosse C. Textbook of Anatomy, 4th edn. New York, NY/Philadelphia, PA: Harper and Row, 1985. p 871.

[5]. Ginsberg LE. Skull-base foramina of the middle cranial fossa: reassessment of normal variation with high resolution CT. AJNR Am J Neuroradiol1994; 15:283-291.

[6]. Haas LL. The posterior condylar fossa, foramen and canal, and the jugular foramen. Radiology 1957;69:546- 55.

[7]. Standring Suzan. Gray's Anatomy: Anatomical Basis of Clinical Practice. 40th edn. Elsevier, Churchill Livingstone. London. 2008:432-433.

[8]. Boyd G. The emissary foramina of the cranium in man and anthropoids. Journal of anatomy. 1930;65:108- 121
[9]. Dimple Dev V., Suman U., Shubha R. Study of incidence, laterality and patency of the posterior condylar canal in 100 dry human skulls. Int J. Anat. Res 2015, Vol 3(1):831-34. ISSN 2321- 4287.

[10]. Krause W. The posterior condylar canal. In: Testut L, Latarjet A, eds. Treaty of Human Anatomy. Barcelona, Spain: Salvat; 1988. Vol 1. pp. 152-158.

[11]. Manoj Kumar. Variations of Posterior Condylar Canal in South Indian Skulls. J. Pharm. Sci. \& Res. Vol. 7(9), 2015, 762-763.

[12]. S Kavitha, A Anand. A study of the condylar canal and its incidence, morphology and clinical significance. Int j. cur res rev, jan 2013; 05(02): 66-70.

\footnotetext{
How to cite this article:

Dakshayani K.R, Uma Shivanal. STUDY OF POSTERIOR CONDYLAR

CANAL IN ADULT HUMAN SKULLS AND ITS CLINICAL IMPORTANCE. Int J Anat Res 2020;8(1.2):7338-7341. DOI: 10.16965/ijar.2019.373
} 